\title{
Serum human epididymis protein 4 level as a predictor of clinical worsening in idiopathic pulmonary arterial hypertension: a pilot study
}

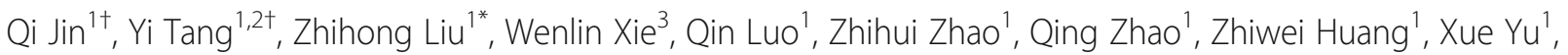
Lu Yan ${ }^{1}$, Changming Xiong ${ }^{1}$, Xinhai $\mathrm{Ni}^{1}$ and Yinkun Yan $^{4}$

\begin{abstract}
Background: Human epididymis protein 4 (HE4) was proved to be a novel biomarker for left heart failure. The purpose of this exploratory study was to evaluate the role of HE4 in patients with idiopathic pulmonary arterial hypertension (IPAH) who usually have concurrent right heart failure.

Methods: 55 patients with newly diagnosed IPAH were continuously enrolled and serum HE4 levels were assessed at baseline. All patients were followed up from the date of blood sampling, and a composite endpoint of clinical worsening was detailedly recorded.

Results: Serum levels of HE4 were significantly higher in IPAH patients than healthy controls $(6.9 \pm 2.2 \mathrm{vs} 4.4 \pm 0.9 \mathrm{ng} / \mathrm{ml}$, $p<0.05)$ and increased as cardiac function deteriorated. HE4 levels correlated with endothelin-1 $(r=0.331, p<0.01)$ and right atrial pressure $(r=0.30, p<0.03)$. After a mean follow-up of $20 \pm 10$ months, 13 patients experienced clinical worsening. Receiver operating characteristic analysis showed that HE4 levels $>6.5 \mathrm{ng} / \mathrm{ml}$ discriminated clinical worsening with a sensitivity of $92.31 \%$ and a specificity of $59.52 \%$ (area under the curve $[A \cup C]=0.81$ ). Multivariate Cox regression analysis demonstrated that HE4 ( $x^{2}: 5.10$; hazard ratio $[H R]=1.26$; $95 \%$ confidence interval: 1.03 to $1.55, p<0.02$ ) and pulmonary vascular resistance $\left(x^{2}: 4.19 ; \mathrm{HR}=1.14 ; 95 \%\right.$ confidence interval: 1.00-1.29, $\left.p<0.04\right)$ were independently predictive of clinical worsening. Patients with HE4 $>6.5 \mathrm{ng} / \mathrm{ml}$ had a worse 2 -year survival rate than those with HE4 $\leq 6.5 \mathrm{ng} / \mathrm{ml}(58.9 \%$ vs 96.2\%, $p<0.001)$.
\end{abstract}

Conclusions: Serum levels of HE4 were elevated in IPAH patients and correlated with disease severity. HE4 was an independent predictor of clinical worsening in IPAH patients.

Keywords: Human epididymis protein 4, Idiopathic pulmonary arterial hypertension, Cardiac function, Predictor, Clinical worsening

\footnotetext{
* Correspondence: zhihongliufuwai@163.com

${ }^{\dagger} \mathrm{Qi}$ Jin and Yi Tang contributed equally to this work.

'State Key Laboratory of Cardiovascular Disease, Center for Pulmonary

Vascular Diseases, Fuwai Hospital, National Center for Cardiovascular

Diseases, Chinese Academy of Medical Sciences and Peking Union Medical

College, 167 Beilishi Road, Xicheng District, Beijing 100037, China

Full list of author information is available at the end of the article
}

(C) The Author(s). 2020 Open Access This article is licensed under a Creative Commons Attribution 4.0 International License, which permits use, sharing, adaptation, distribution and reproduction in any medium or format, as long as you give appropriate credit to the original author(s) and the source, provide a link to the Creative Commons licence, and indicate if changes were made. The images or other third party material in this article are included in the article's Creative Commons licence, unless indicated otherwise in a credit line to the material. If material is not included in the article's Creative Commons licence and your intended use is not permitted by statutory regulation or exceeds the permitted use, you will need to obtain permission directly from the copyright holder. To view a copy of this licence, visit http://creativecommons.org/licenses/by/4.0/ The Creative Commons Public Domain Dedication waiver (http://creativecommons.org/publicdomain/zero/1.0/) applies to the data made available in this article, unless otherwise stated in a credit line to the data. 


\section{Background}

Pulmonary arterial hypertension (PAH) is a life-threatening condition characterized by extensive narrowing and obliteration of the pulmonary vasculature, leading to increased pulmonary vascular resistance (PVR) and subsequent right heart failure and terminal death. The US-REVEAL registry displayed a low 5-year survival rate of $61.2 \%$ in patients with newly diagnosed PAH [1]. Therefore, early diagnosis and prognostic stratification are important for the optimal therapeutic strategies for PAH patients. Circulating biomarkers, such as N-terminal prohormone brain-type natriuretic peptide (NT-proBNP), endothelin (ET)-1 and growth differentiation factor-15, have been proposed as parameters for diagnostic and prognostic evaluation. Nevertheless, these biomarkers do not fully reflect all features of the complex pathophysiology of $\mathrm{PAH}$ [2]. Therefore, the quest for new biomarkers is highly desirable.

Human epididymis protein 4 (HE4) was originally identified as a secreted protein in the human epididymis [3]. It was mildly expressed in other organs such as kidney and respiratory tract [4]. HE4 could suppress the activity of multiple proteases such as serine proteases and matrix metalloproteinases, specifically inhibit degradation of type I collagen, and mediate kidney fibrosis [5]. Interestingly, HE4 correlated with acute and chronic left heart failure severity and predicted adverse outcomes in heart failure, and the strong correlation between HE4 and galectin-3 or fibroblast growth factor 23 demonstrated that cardiac fibrosis was putatively involved in the pathogenic process $[6,7]$. However, the role of HE4 has not been evaluated in patients with idiopathic pulmonary arterial hypertension (IPAH), who usually die of right heart failure characterized by right ventricular fibrosis and remodeling. Therefore, this pilot study aimed to assess the prognostic value of HE4 in IPAH patients.

\section{Methods}

\section{Study population}

Between February 2013 and November 2015, 55 adult patients with newly diagnosed IPAH admitted to Fuwai Hospital were enrolled in the study. IPAH was defined according to the guideline [8]. Patients with the following conditions were excluded due to potential interference in HE4 concentrations: 1). current smoker, 2). recent pregnancy, 3). cancer, and 4). chronic renal failure [9]. The control group was age- and sex-matched healthy subjects without the above conditions. This study was conducted in compliance with the Declaration of Helsinki and was approved by the institutional review board of Fuwai Hospital. All patients signed written informed consent.

\section{Clinical assessment and follow-up}

Diagnostic right heart catheterization (RHC) was performed using standard hemodynamic measurements at baseline as previously described [10]. Basic demographics such as body mass index (BMI) and World Health Organization functional class (WHO-FC) and biochemical tests were collected at baseline. Serum NT-proBNP and ET-1 concentrations were measured using commercially available ELISA kits (Biomedica GmbH, Vienna, Austria).

Patients were followed-up every 3 months for 1 year and every 6 months later after discharge. The composite end point was defined as the time from the date of blood sampling to the first clinical worsening (CW) event, including all-cause mortality, lung transplantation, hospitalization for $\mathrm{PAH}$ worsening, need for intravenous epoprostenol therapy, and interventional procedures (balloon atrial septostomy), as previously reported [11]. The follow-up time was calculated from the time of blood sampling to May 1, 2016.

\section{HE4 measurement}

Peripheral venous blood samples were collected the next day morning after RHC. Blood samples for the measurement of HE4 were tubed with ethylenediaminetetraacetic acid anticoagulant and centrifuged for $15 \mathrm{~min}$ at 3000 rpm within $30 \mathrm{~min}$ of collection. Serum samples were then stored at $-80{ }^{\circ} \mathrm{C}$ for further analysis. Hemolyzed specimens were kicked out before experiments. Serum levels of HE4 were measured using the Quantikine human HE4/ Whey acidic protein four-disulfide core domain 2 (WFDC2) immunoassay (R\&D systems, Inc., USA \& Canada). The minimum detectable dose of human HE4 ranged from 2.44 to $32.2 \mathrm{pg} / \mathrm{ml}$. The intraand inter-assay coefficients of variation were less than 3.5 and $5.9 \%$ respectively. All measurements were performed by an investigator blinded to the clinical data.

\section{Statistical analysis}

The data were presented as mean \pm standard deviation for continuous variables or as percentages for categorical variables. Statistical differences between two groups were analyzed using an independent Student's t test for normally distributed variables and Mann-Whitney $U$ test for non-normally distributed variables. The data were visually inspected for normality and outliers using scatter plots. Chi-square test was used for categorical variables. Correlations between HE4 and other variables were explored using Pearson or Spearman correlation coefficients as appropriate. The optimal cutoff value of HE4 was determined by receiver operating characteristic (ROC) curve analysis. Univariate Cox regression analysis was used to explore the predictive value of each variable for clinical worsening, and then a forward stepwise multivariate Cox regression model was further used to evaluate variables with $p<0.05$. Kaplan-Meier plots with log-rank tests illustrated outcomes of patients grouped 
Table 1 Baseline characteristics between CW and Non-CW IPAH patients

\begin{tabular}{|c|c|c|c|c|}
\hline Variables & Total $(n=55)$ & CW $(n=13)$ & Non-CW $(n=42)$ & $P$ Value \\
\hline Age, years & $31 \pm 9$ & $34 \pm 8$ & $30 \pm 10$ & 0.11 \\
\hline Female, n (\%) & 46(83.6) & $11(84.6)$ & $35(83.3)$ & 1.0 \\
\hline $\mathrm{BMI}, \mathrm{kg} / \mathrm{m}^{2}$ & $22.6 \pm 3.0$ & $21.7 \pm 2.5$ & $22.9 \pm 3.1$ & 0.18 \\
\hline WHO-FC III-IV, n (\%) & $27(49.1)$ & $9(69.2)$ & $18(42.8)$ & 0.12 \\
\hline \multicolumn{5}{|l|}{ Laboratory tests } \\
\hline Creatinine, $\mu \mathrm{mol} / / \mathrm{l}$ & $71.3 \pm 15.2$ & $74.1 \pm 18.8$ & $70.5 \pm 14.0$ & 0.46 \\
\hline Uric acid, $\mu \mathrm{mol} / \mathrm{l}$ & $443.2 \pm 131.0$ & $469.7 \pm 172.1$ & $435.0 \pm 116.8$ & 0.41 \\
\hline $\mathrm{HsCRP}, \mathrm{mg} / \mathrm{l}$ & $1.7 \pm 1.6$ & $1.5 \pm 1.5$ & $1.8 \pm 1.6$ & 0.44 \\
\hline NT-proBNP, pg/ml & $1181.8 \pm 1102.3$ & $1389.4 \pm 1505.2$ & $1117.6 \pm 958.8$ & 0.84 \\
\hline ET-1, fmol/ml & $0.5 \pm 0.6$ & $0.7 \pm 0.8$ & $0.5 \pm 0.5$ & 0.62 \\
\hline $\mathrm{HE} 4, \mathrm{ng} / \mathrm{ml}$ & $6.9 \pm 2.2$ & $8.8 \pm 2.5$ & $6.3 \pm 1.7$ & 0.001 \\
\hline \multicolumn{5}{|l|}{ Hemodynamics } \\
\hline $\mathrm{RAP}, \mathrm{mmHg}$ & $4.9 \pm 4.7$ & $8.0 \pm 5.1$ & $4.0 \pm 4.2$ & 0.01 \\
\hline $\mathrm{mPAP}, \mathrm{mmHg}$ & $50.1 \pm 10.6$ & $51.5 \pm 9.0$ & $49.7 \pm 11.0$ & 0.59 \\
\hline PCWP, mmHg & $6.6 \pm 2.8$ & $7.2 \pm 2.9$ & $6.4 \pm 2.8$ & 0.30 \\
\hline PVR, Wood units & $10.8 \pm 4.7$ & $12.3 \pm 5.3$ & $10.3 \pm 4.5$ & 0.19 \\
\hline $\mathrm{Cl}, \mathrm{L} \cdot \mathrm{min}^{-1} \cdot \mathrm{m}^{-2}$ & $2.8 \pm 0.9$ & $2.5 \pm 0.6$ & $2.9 \pm 0.9$ & 0.23 \\
\hline $\mathrm{SvO}_{2}, \%$ & $70.5 \pm 7.3$ & $68.7 \pm 6.7$ & $71.0 \pm 7.4$ & 0.47 \\
\hline
\end{tabular}

by the optimal cutoff value of HE4. Statistical analyses were performed using SPSS version 19.0 (SPSS, Inc). A two-sided $p$-value $<0.05$ was considered statistically significant.

\section{Results}

Baseline characteristics

Fifty-five IPAH patients ( $31 \pm 9$ years, $83.6 \%$ female) were enrolled in our study. The numbers of patients in WHO-FC I/II/III/IV were 3/25/26/1 respectively. Their mean PVR was $10.8 \pm 4.7$ Wood units with a mean cardiac index $(\mathrm{CI})$ of $2.8 \pm 0.9 \mathrm{~L} \cdot \mathrm{min}^{-1} \cdot \mathrm{m}^{-2} .50$ (90.9\%) patients were treated with monotherapy (39 with phosphodiesterase type 5 inhibitors, 9 with endothelin receptor antagonists and 2 with prostacyclin), 2 patients received combination therapy and three were treated with calcium channel blockers. Their baseline characteristics were summarized in Table 1.

\section{Comparison between groups}

15 healthy volunteers were enrolled in our study. Age and sex did not differ between IPAH patients and healthy controls. Interestingly, HE4 levels were notably higher among IPAH patients compared to those of control subjects $(6.9 \pm 2.2$ vs $4.4 \pm 0.9 \mathrm{ng} / \mathrm{ml}, p<0.001$, Fig. 1$)$. In addition, HE4 levels in WHO-FC III/IV patients were significantly increased compared to those in WHO-FC I/
II $(7.7 \pm 2.7$ vs $6.2 \pm 1.2 \mathrm{ng} / \mathrm{ml}, p<0.009)$. HE4 levels correlated positively with ET-1 $(r=0.331, p<0.01)$ and right atrial pressure (RAP) $(r=0.30, p<0.03)$. However, no significant correlations were observed between HE4 and other variables.

The mean follow-up duration was $20 \pm 10$ months, and no patients were lost to follow-up. Four patients died (three for right heart failure and one for sudden death), one underwent lung transplantation and eight worsened. Comparison between the parameters of $\mathrm{CW}$ and non-

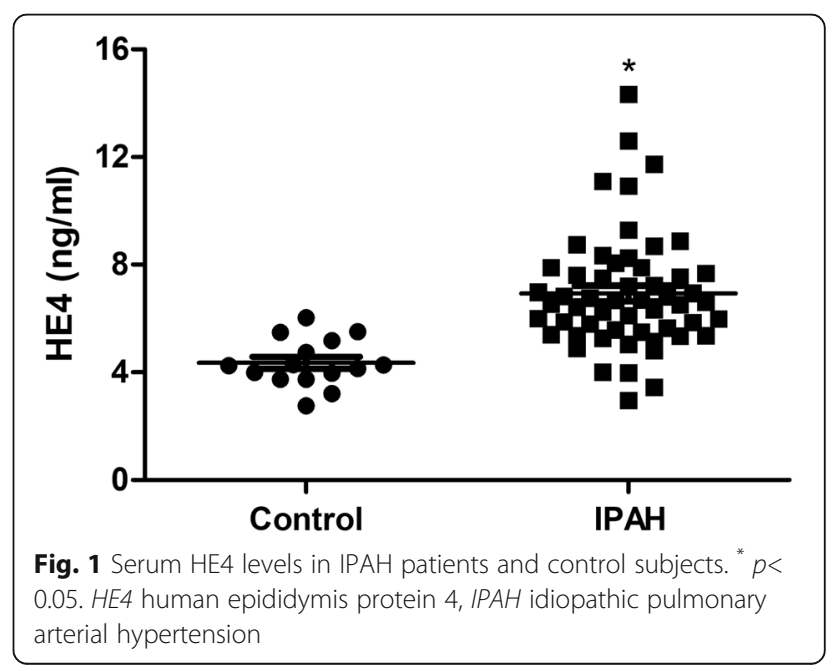


$\mathrm{CW}$ patients was shown in Table 1 , and no differences were observed in sex, age, and BMI between the two groups. Only HE4 and RAP in CW patients were significantly higher than those in non-CW patients, and none of other clinical variables were significantly different.

\section{HE4 and clinical outcomes}

The ROC analysis showed HE4 levels $>6.5 \mathrm{ng} / \mathrm{ml}$ predicted clinical worsening with a sensitivity of $92.3 \%$, a specificity of $59.5 \%$, and the area under the curve (AUC) of $0.81 \quad(p<0.001$, Fig. 2). Furthermore, HE4 outperformed other prognostic markers such as $\mathrm{CI}$ (AUC $=$ $0.61, p=0.03)$, PVR (AUC $=0.60, p=0.03)$ and NTproBNP $(\mathrm{AUC}=0.52, p=0.001)$.

In univariate analysis, HE4 (hazard ratio $[\mathrm{HR}]=1.30$, 95\% confidence interval [CI]: 1.06-1.59, $p=0.01$ ), WHO-FC $(\mathrm{HR}=4.05,95 \% \mathrm{CI}: 1.18-13.91, p=0.02)$, RAP $(\mathrm{HR}=1.15,95 \%$ CI: $1.03-1.29, \quad p=0.02), \quad$ PVR $(\mathrm{HR}=1.15,95 \% \mathrm{CI}: 1.02-1.29, p=0.03)$ and $\mathrm{CI}(\mathrm{HR}=$ $0.36,95 \%$ CI: $0.14-0.93, p=0.04$ ) were all significant predictors of $\mathrm{CW}$. Multivariable forward stepwise Cox analysis was performed including HE4, WHO-FC, RAP, PVR and CI, showing HE4 $\left(\chi^{2}: 5.10 ; \mathrm{HR}=1.26\right.$; 95\% CI: $1.03-1.55, p<0.02)$ and PVR $\left(x^{2}: 4.19 ; \mathrm{HR}=1.14 ; 95 \%\right.$ CI: $1.00-1.29, p<0.04)$ could independently predict clinical worsening.
Kaplan-Meier survival curves were shown in Fig. 3. Patients with HE4 $>6.5 \mathrm{ng} / \mathrm{ml}$ had a worse 2-year survival rate than those with HE4 $\leq 6.5 \mathrm{ng} / \mathrm{ml}(58.9 \%$ vs $96.2 \%$, $p<0.001$ ). The unadjusted HR was 10.52 (95\% CI: 1.3383.65), and the HR after adjustment for age, sex, and BMI was 10.74 (95\% CI: 1.26-9.48).

\section{Discussion}

To the best of our knowledge, this is the first study to prove that elevated serum HE4 levels could serve as a novel biomarker for IPAH patients. Herein, we revealed that HE4 enhanced as cardiac function deteriorated, and correlated with ET-1 and RAP. Moreover, our present study demonstrated HE4 was a powerful independent prognostic factor for clinical worsening in IPAH patients. The significant increase of serum HE4 level may indicate a poor prognosis, and early intensive targeted therapy for patients with high HE4 level may improve their clinical outcomes.

HE4, also known as WFDC2, was mildly to moderately expressed in epididymis, kidney, respiratory tract, and salivary glands [4]. Several studies reported serum HE4 was overexpressed in ovarian cancer and lung cancer patients $[12,13]$, and it might also play a role during innate immune defense and tumorigenesis [14, 15]. Fibroblastderived HE4 could mediate kidney fibrosis via suppressing

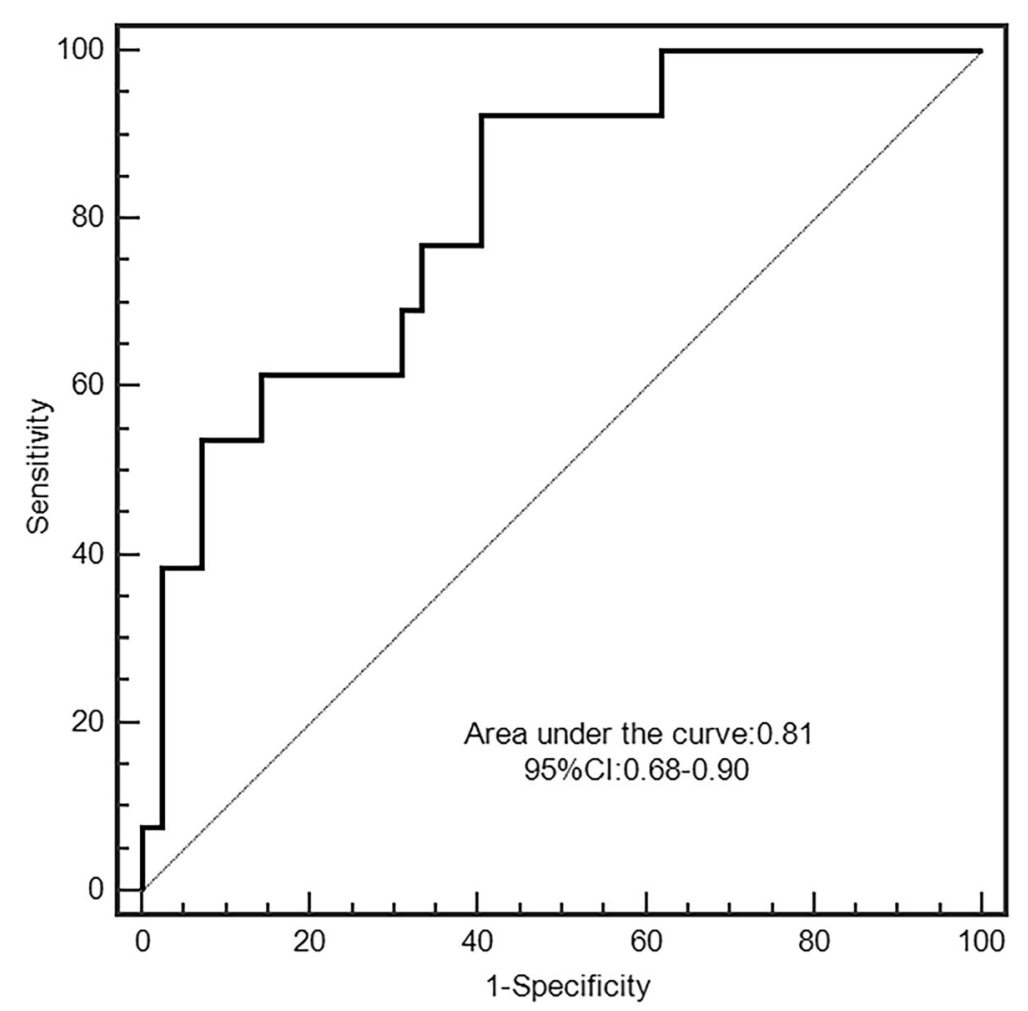

Fig. 2 ROC curve showing the sensitivity and specificity of HE4 to predict clinical worsening. ROC receiver operating characteristic, HE4 human epididymis protein 4 


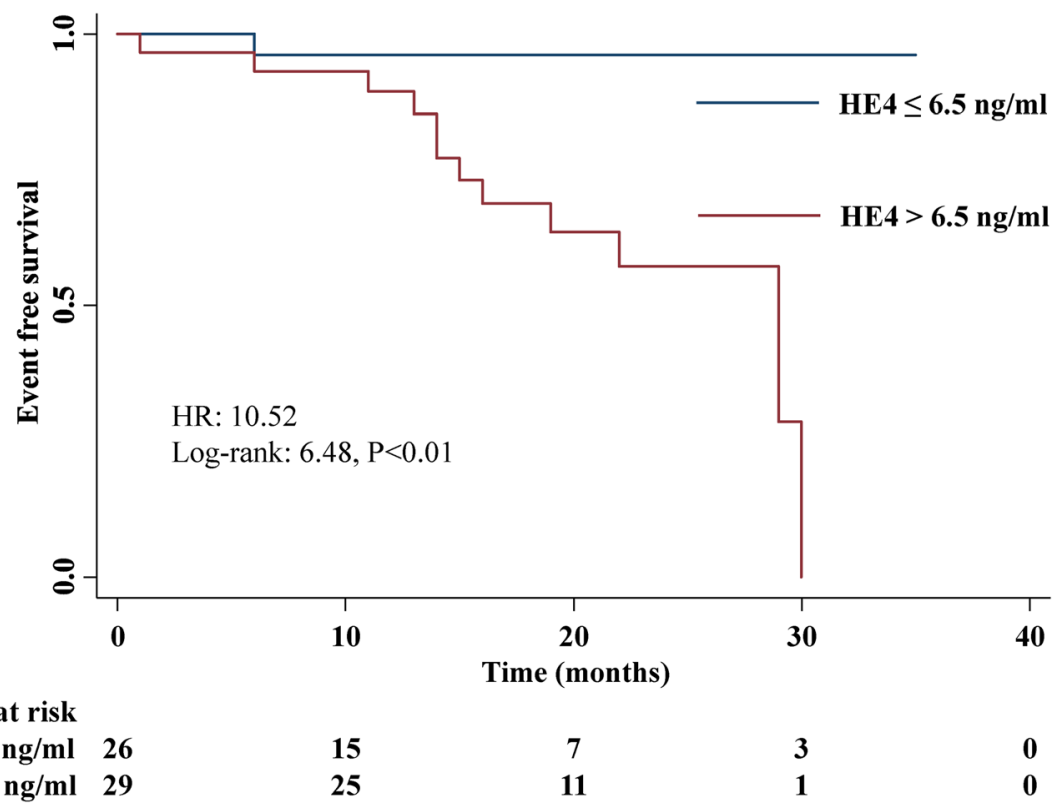

Fig. 3 Kaplan-Meier analysis of serum HE4 levels for clinical worsening. HE4 human epididymis protein 4, HR hazard ratio

the activity of multiple proteases, such as serine proteases and matrix metalloproteinases, which could be inhibited by HE4 neutralizing antibodies in mouse models [5]. Additionally, HE4 levels were elevated in patients suffering from chronic kidney disease and left heart failure [6, 7 , 16], denoting that HE4 could potentially play an essential role in renal and cardiac fibrosis.

Our study illustrated that HE4 levels were higher in IPAH patients than healthy controls, and its levels increased as cardiac function deteriorated, which was consistent with previous studies among left heart failure patients [6, 7]. Furthermore, HE4 had a weak but significant positive correlation with RAP and ET-1, and elevated RAP indicates right ventricular dysfunction, predicts poor outcome in PAH patients [17], and is usually triggered by cardiac fibrosis [18]. Elevated ET-1 levels could also independently predict clinical worsening in IPAH patients treated with Bosentan, and ET-1 played a crucial role in vascular and tissue fibrosis [19, 20]. In addition, HE4 had a strong positive correlation with galectin-3, a biomarker of cardiac fibrosis, indicating that HE4 might function in cardiac fibrosis [7]. These evidences might establish a link among HE4, RAP and ET-1. However, HE4 was not correlated with NTproBNP and creatinine, which might be ascribed to the small sample size and limited number of patients in WHO-FC I or IV.

IPAH is characterized by pulmonary vascular remodeling, and IPAH patients generally die from right heart failure. Extracellular matrix protein collagen and fibrosis are the key factors involved in pulmonary vascular remodeling and right heart failure [21, 22]. Although we suspected that HE4 could potentially play a crucial role in cardiac fibrosis, the exact mechanism between HE4 and right heart failure as well as pulmonary vascular remodeling remains largely unknown.

Our study has several limitations. First, the relatively small sample size and few clinical events might create potential bias, as this is only a preliminary study to investigate the possible role of HE4 in pulmonary vascular disease and right heart failure, the population size is being expanded for further validation. Second, HE4 levels were detected only at baseline, and changes in HE4 levels after treatment were unknown. Third, we did not measure levels of galectin-3 and matrix metalloproteinase $2 / 9$, which might provide additional mechanistic insights into the link between HE4 and IPAH. Therefore, further large sample studies are needed to investigate the role of HE4 in IPAH patients.

\section{Conclusion}

Serum levels of HE4 were elevated in patients with IPAH and could independently predict clinical worsening. HE4 might be a novel biomarker for IPAH.

\section{Abbreviations}

PAH: Pulmonary arterial hypertension; PVR: Pulmonary vascular resistance; NT-proBNP: N-terminal prohormone brain-type natriuretic peptide; ET1: Endothelin-1; HE4: Human epididymis protein 4; IPAH: Idiopathic pulmonary arterial hypertension; RHC: Right heart catheterization; BMI: Body mass index; WHO-FC: World health organization functional class; CW: Clinical worsening; WFDC2: Whey acidic protein four-disulfide core domain 2; ROC: Receiver operating characteristic; Cl: Cardiac index; RAP: Right atrial pressure; AUC: Area under the curve 


\section{Acknowledgments}

We would like to thank Chengzhi Yang (Fuwai hospital, Chinese Academy of Medical Sciences) for technical assistance of ELISA and Long Zhou (Fuwai hospital, Chinese Academy of Medical Sciences) for his assistance in statistical analysis. The abstract was presented in the form of E-poster Short Oral in CHEST Congress 2019 held in Bangkok, Thailand on 10-12 April 2019.

\section{Authors' contributions}

QJ and YT designed the study, analyzed the results, and drafted the manuscript. WLX, QL, ZHZ, QZ, ZWH, XY, LY, CMX, XHN and YKY recruited patients, conducted the study, and participated in data analysis. ZHL designed the study, interpreted the data and revised the manuscript. All authors read and approved the final manuscript.

\section{Funding}

This work was supported by the National Natural Science Foundation of China (Nos. 81641005, 81370326, 81800056) and National Precision Medical Research Program of China (2016YFC0905602). The funders had no role in the design of the study, the collection, analysis, and interpretation of data and in writing the manuscript.

\section{Availability of data and materials}

The datasets used and analyzed during the present study are available from the corresponding author on reasonable request.

\section{Ethics approval and consent to participate}

The study was approved by the ethics committee of Fuwai Hospital and adhered to the Declaration of Helsinki. Written informed consent was obtained from patients in this study.

\section{Consent for publication}

Not applicable.

\section{Competing interests}

The authors declare that they have no competing interests.

\section{Author details}

${ }^{1}$ State Key Laboratory of Cardiovascular Disease, Center for Pulmonary Vascular Diseases, Fuwai Hospital, National Center for Cardiovascular Diseases, Chinese Academy of Medical Sciences and Peking Union Medical College, 167 Beilishi Road, Xicheng District, Beijing 100037, China. ${ }^{2}$ Department of Cardiology, Hunan Provincial People's Hospital, The First Affiliated Hospital of Hunan Normal University, The College of Clinical Medicine of Hunan Normal University, Changsha, China. ${ }^{3}$ Department of Pathology, The Seventh Affiliated Hospital of Sun Yat-sen University, Shenzhen, China. ${ }^{4}$ Department of Epidemiology, Capital institute of Pediatrics, Beijing, China.

Received: 24 July 2019 Accepted: 1 April 2020

Published online: 15 April 2020

\section{References}

1. Benza RL, Miller DP, Barst RJ, Badesch DB, Frost AE, McGoon MD. An evaluation of long-term survival from time of diagnosis in pulmonary arterial hypertension from the REVEAL registry. Chest. 2012;142:448-56

2. Pezzuto B, Badagliacca R, Poscia R, Ghio S, D'Alto M, Vitulo P, et al. Circulating biomarkers in pulmonary arterial hypertension: update and future direction.J Heart Lung Transplant. 2015:34:282-305.

3. Kirchhoff C, Habben I, Ivell R, Krull N. A major human epididymis-specific CDNA encodes a protein with sequence homology to extracellular proteinase inhibitors. Biol Reprod. 1991;45:350-7.

4. Galgano MT, Hampton GM, Frierson HJ. Comprehensive analysis of HE4 expression in normal and malignant human tissues. Mod Pathol. 2006;19: 847-53.

5. LeBleu VS, Teng Y, O'Connell JT, Charytan D, Muller GA, Muller CA, et al. Identification of human epididymis protein-4 as a fibroblast-derived mediator of fibrosis. Nat Med. 2013:19:227-31.

6. de Boer RA, Cao Q, Postmus D, Damman K, Voors AA, Jaarsma T, et al. The WAP four-disulfide core domain protein HE4: a novel biomarker for heart failure. JACC Heart Fail. 2013;1:164-9.
7. Piek A, Meijers WC, Schroten NF, Gansevoort RT, de Boer RA, Sillje HH. HE4 serum levels are associated with heart failure severity in patients with chronic heart failure. J Card Fail. 2017;23:12-9.

8. Galie N, Hoeper MM, Humbert M, Torbicki A, Vachiery JL, Barbera JA, et al. Guidelines for the diagnosis and treatment of pulmonary hypertension the task force for the diagnosis and treatment of pulmonary hypertension of the European Society of Cardiology (ESC) and the European Respiratory Society (ERS), endorsed by the International Society of Heart and Lung Transplantation (ISHLT). Eur Heart J. 2009:30:2493-537.

9. Ferraro $S$, Schiumarini D, Panteghini M. Human epididymis protein 4: factors of variation. Clin Chim Acta. 2015:438:171-7.

10. Zhang $\mathrm{HL}$, Liu ZH, Wang $\mathrm{Y}$, Xiong $\mathrm{CM}$, Ni XH, He JG, et al. Acute responses to inhalation of lloprost in patients with pulmonary hypertension. Chin Med J (Engl). 2012;125:2826-31

11. Tang Y, Luo Q, Liu Z, Ma X, Zhao Z, Huang Z, et al. Oxygen uptake efficiency slope predicts poor outcome in patients with idiopathic pulmonary arterial hypertension. J Am Heart Assoc. 2017;6:e005037.

12. Zhu L, Zhuang H, Wang H, Tan M, Schwab CL, Deng L, et al. Overexpression of HE4 (human epididymis protein 4) enhances proliferation, invasion and metastasis of ovarian cancer. Oncotarget. 2016;7:729-44.

13. Zeng $Q$, Liu M, Zhou N, Liu L, Song X. Serum human epididymis protein 4 (HE4) may be a better tumor marker in early lung cancer. Clin Chim Acta. 2016:455:102-6.

14. Bingle L, Cross SS, High AS, Wallace WA, Rassl D, Yuan G, et al. WFDC2 (HE4): a potential role in the innate immunity of the oral cavity and respiratory tract and the development of adenocarcinomas of the lung. Respir Res. 2006;7:61.

15. Bouchard D, Morisset D, Bourbonnais Y, Tremblay GM. Proteins with wheyacidic-protein motifs and cancer. Lancet Oncol. 2006;7:167-74.

16. Wan J, Wang Y, Cai G, Liang J, Yue C, Wang F, et al. Elevated serum concentrations of HE4 as a novel biomarker of disease severity and renal fibrosis in kidney disease. Oncotarget. 2016;7:67748-59.

17. Austin C, Alassas K, Burger C, Safford R, Pagan R, Duello K, et al. Echocardiographic assessment of estimated right atrial pressure and size predicts mortality in pulmonary arterial hypertension. Chest. 2015;147:198-208.

18. Frangogiannis NG. Fibroblasts and the extracellular matrix in right ventricular disease. Cardiovasc Res. 2017:113:1453-64.

19. Vizza CD, Letizia C, Badagliacca R, Poscia R, Pezzuto B, Gambardella C, et al. Relationship between baseline ET-1 plasma levels and outcome in patients with idiopathic pulmonary hypertension treated with bosentan. Int J Cardiol. 2013;167:220-4.

20. Wermuth PJ, Li Z, Mendoza FA, Jimenez SA. Stimulation of transforming growth factor-beta1-induced endothelial-to-Mesenchymal transition and tissue fibrosis by Endothelin-1 (ET-1): a novel Profibrotic effect of ET-1. PLoS One. 2016;11:e161988.

21. Schreier D, Hacker T, Song G, Chesler N. The role of collagen synthesis in ventricular and vascular adaptation to hypoxic pulmonary hypertension. J Biomech Eng. 2013:135:021018

22. Golob MJ, Wang Z, Prostrollo AJ, Hacker TA, Chesler NC. Limiting collagen turnover via collagenase-resistance attenuates right ventricular dysfunction and fibrosis in pulmonary arterial hypertension. Physiol Rep. 2016;4:e12815.

\section{Publisher's Note}

Springer Nature remains neutral with regard to jurisdictional claims in published maps and institutional affiliations.

\section{Ready to submit your research? Choose BMC and benefit from:}

- fast, convenient online submission

- thorough peer review by experienced researchers in your field

- rapid publication on acceptance

- support for research data, including large and complex data types

- gold Open Access which fosters wider collaboration and increased citations

- maximum visibility for your research: over $100 \mathrm{M}$ website views per year

At $\mathrm{BMC}$, research is always in progress.

Learn more biomedcentral.com/submission 